\title{
USE OF SIMULATION IN A FACTORY FOR BUSINESS CONTINUITY PLANNING
}

\author{
Tan, Y.* \& Takakuwa, S.* \\ *Tokyo University of Science, School of Management, \\ 500 Shimokiyoku, Saitama Prefecture, 346-8512, Japan \\ ${ }^{* *}$ Nagoya University, Graduate School of Economics and Business Administration, \\ Furo-cho, Chikusa-ku, Nagoya, Aichi 464-8601, Japan \\ E-Mail: tan@ms.kuki.tus.ac.jp; takakuwa@soec.nagoya-u.ac.jp
}

\begin{abstract}
Companies can suffer significant losses as a result of unanticipated business disruptions caused by natural disasters or outbreaks of disease. In order to restore the organization's critical functions and minimize the impacts of a disruption, it is important to establish business continuity planning and recovery planning. First the risks in the external environment surrounding the companies and business continuity planning were described. Then, how the computer-based simulation technique could be utilized to establish the business continuity planning was examined under a pandemic environment. In this study, an approach of examining the operation rates and the plant-utilization rates was proposed for a factory, by applying simulation. The proposed approach was applied to a real manufacturer especially under a pandemic flu environment in order to confirm its effectiveness.

(Received in July 2010, accepted in November 2010. This paper was with the authors 1 month for 1 revision.)
\end{abstract}

Key Words: Business Continuity Planning, Personnel Planning, Simulation, Pandemic

\section{INTRODUCTION}

Companies can suffer significant financial losses as a result of the serious social and economic disruptions caused by natural disasters and outbreaks of disease [1-3]. This subject has attracted growing attention in recent years because of a series of disasters and outbreaks, including the pandemic (H1N1) influenza (2009), the Sichuan earthquake (2008, China) and the Haiti earthquake (2010, Haiti). Disasters and outbreaks, of course, cannot be anticipated, but their effects on a company may be amplified by the lack of preparedness action [4]. To cope with these types of disruptions immediately and smoothly, the approach of business continuity planning (BCP) is proposed - an approach that has received much attention in recent years [2].

In this study, data from a manufacturer that assembles machines were used in applying business continuity planning. According to a Japanese governmental report, it was expected that approximately 40 percent of company employees would be absent [5]. However, the company should be able to keep producing products ordered by customers. In establishing business continuity planning (BCP), simulation is used to forecast and evaluate the operating rate in a factory. As a result of simulation analysis, a possible policy and plan for job training and job enrichment can be established for responding especially to the pandemic influenza.

\section{RISKS AND BUSINESS CONTINUITY PLANNING}

As shown in Fig.1, there are various risks in the external environment surrounding the companies [6]. For example, the frequency of infectious diseases is relatively high and the 
degree of influence is between medium to great. On the other hand, a large earthquake occurs rarely, but the damage will be great. On July 16, 2007, the magnitude 6.8 Niigata Chuetsu-oki earthquake occurred in the Niigata region of Japan. The earthquake shook the prefecture of Niigata, and the quake was felt as far as Tokyo. The damage was estimated at US\$5 billion. After this earthquake, the RIKEN manufacturing plant - one of the largest parts suppliers to major Japanese automakers, including Toyota and Honda - needed to suspend production of piston rings because production lines and factory buildings had been severely damaged. As a result, 12 auto companies in Japan (downstream of supply chain) were forced to stop auto assembly lines, and 540,000 employees were affected - all because only one kind of part could not supplied by one company. Toyota alone lost production of more than 120,000 cars in the first weeks after the earthquake. The main reason for such serious consequences was neglecting to develop a BCP. From this example we can see that it is important to prepare a BCP.

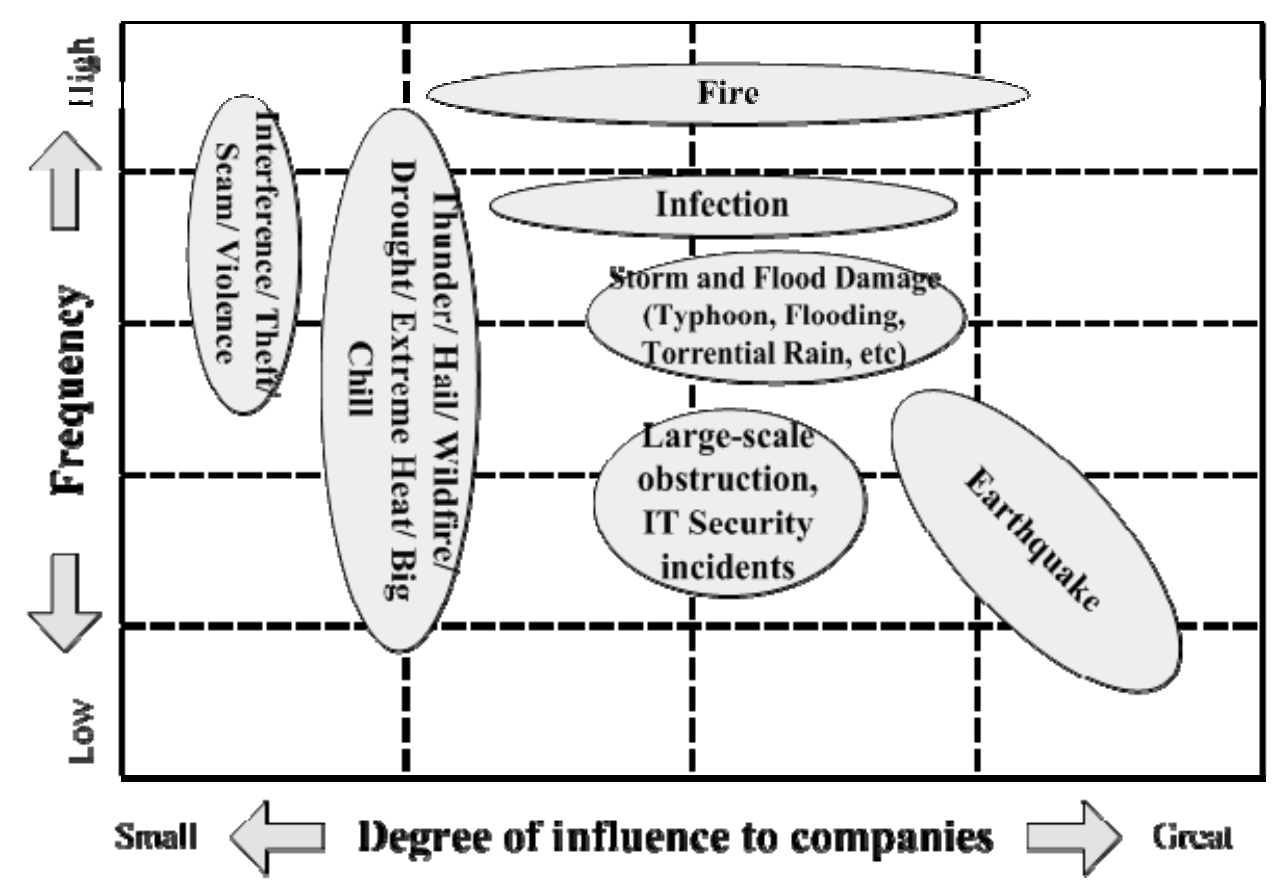

Figure 1: Risks surrounding the companies.

BCP could be described as a system that developed primarily to elaborate how an organization will partially restore its critical functions from a business disruption (i.e., disaster condition); and how to reduce the time to restore condition to a state of "business as usual", so as to minimize the effects of a disruption [1,4]. Its contents typically consist of securing back-up systems and offices, immediate response personnel, and prompt confirmation of safety [7]. It is now generally recognized that business continuity planning and disaster recovery planning are vital activities. In general, however, creating and maintaining a sound business continuity and disaster recovery plan is a complex undertaking involving a series of steps, as shown in Fig. 2 [7].

A BCP developing approach should includes three basic steps which can be described as 1) Indentify the major and potential risks (business interruption), 2) Develop a plan to mitigate or reduce the impact of the indentified risks, and 3) Train employees and test the plan to ensure that it is effective and make it meets the needs of the organization [1, 4]. A procedure of BCP in case of pandemic situation is shown in Fig. 3 [8]. 


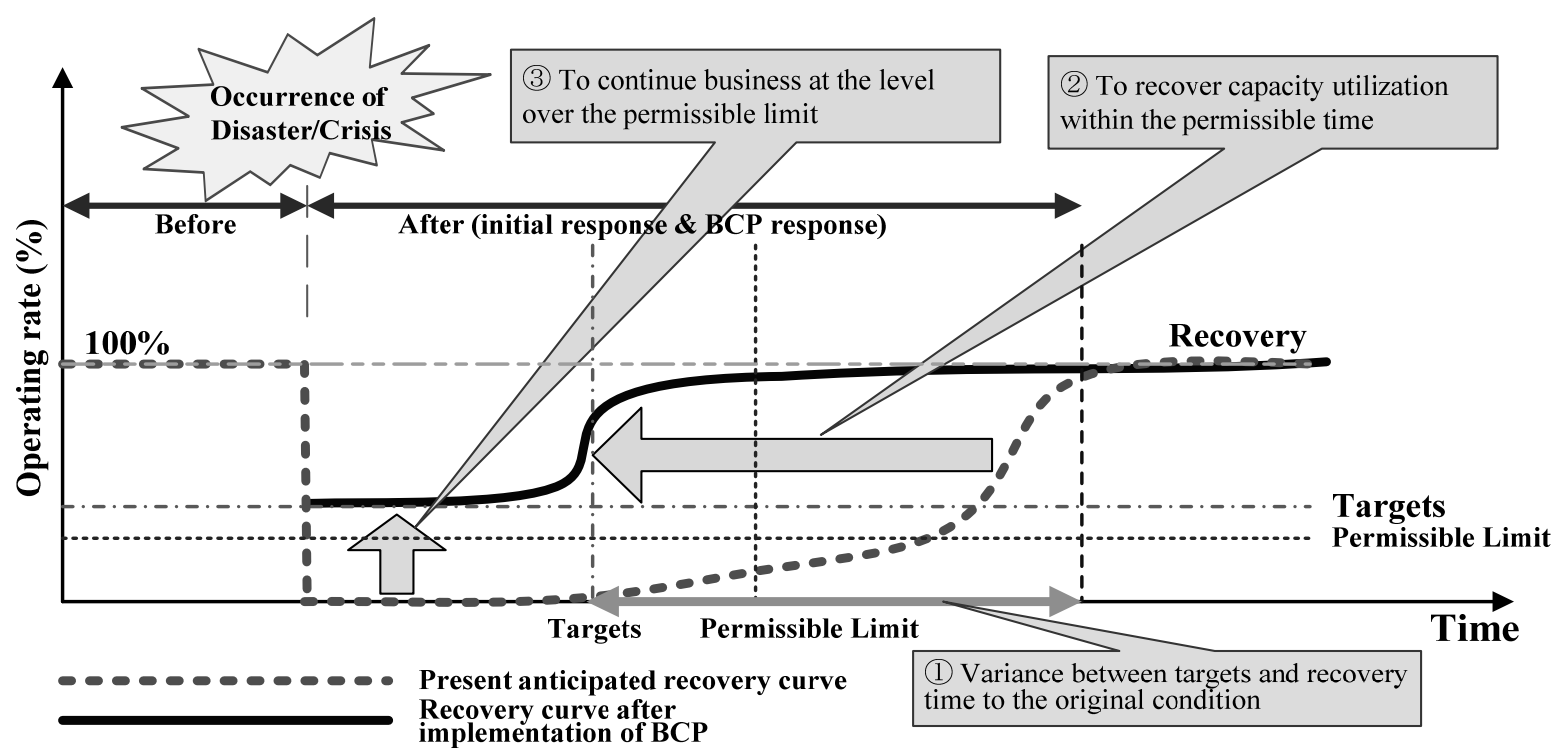

Figure 2: Concept of Business Continuity Planning (Source: Cabinet Office of Japan [7])

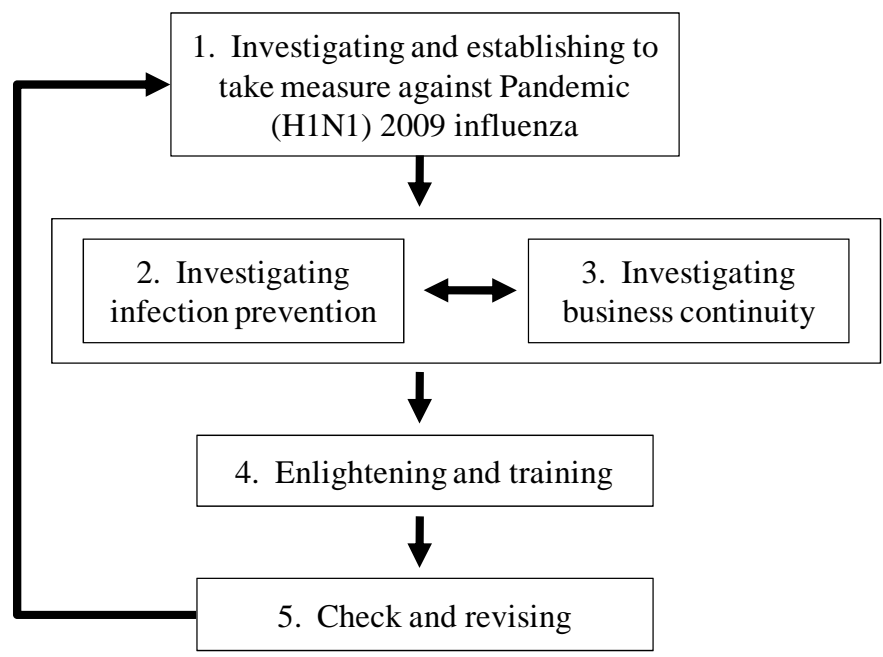

Figure 3: Procedure of business continuity planning in case of pandemic situation.

\section{BCP FOR PANDEMIC INFLUENZA}

As mentioned earlier, companies encounter many risks. In this study, we selected the risk of pandemic influenza. In April 2009, the World Health Organization (WHO) received reports of sustained person-to-person infections with a novel influenza A (H1N1) virus in Mexico and the United States. Subsequent international spread of the disease led WHO to declare on June 11, 2009 that the first influenza pandemic in 41 years had occurred [9]. To facilitate quick and trustworthy countermeasures, the Pandemic Influenza Preparedness Action Plan of the Japanese Government [5] was drafted in compliance with the WHO Global Influenza Preparedness Plan. Table I shows the outline of the action plan.

According to Table I, the expected absentee rate of employees would be $40 \%$ at the maximum during the period of the pandemic phase. We wanted to know at what point the absenteeism rate of employees would reach to $40 \%$ and how the business would respond if that happened. There would be many questions. Would a small- or medium-sized enterprise with few employees have no choice but to suspend its business? Could BCP be adopted to address those problems? 
Table I: Pandemic influenza preparedness action plan of the Japanese government.

\begin{tabular}{|c|c|}
\hline Items & Assumption at the beginning stage of pandemic (Phase 6) \\
\hline Infection rate & $25 \%$ (30\% in Tokyo) \\
\hline $\begin{array}{l}\text { Number of patients seeing } \\
\text { doctors at clinics/hospitals }\end{array}$ & $\begin{array}{l}13 \text { - } 25 \text { million. Number of patients would increase rapidly, and } \\
\text { Sickbeds and medicines: shortage }\end{array}$ \\
\hline Expected absentee rate & 40\% (the maximum) \\
\hline Prevalent period of time & 8 weeks. Multiple occurrence s. \\
\hline Management (finance) & Possible confusion on getting funds, payment, etc. \\
\hline $\begin{array}{l}\text { Electricity, natural gas, water } \\
\text { service, communication lines }\end{array}$ & $\begin{array}{l}\text { Keeping the facilities in good working order. Other business } \\
\text { operations will be moderated, or suspended. }\end{array}$ \\
\hline Public transport & Service level would be reduced. \\
\hline Finance & Settlement and ATM available \\
\hline Logistics & $\begin{array}{l}\text { Collection and delivery delayed. Home parcel delivery and mail- } \\
\text { order business increased. }\end{array}$ \\
\hline Administration service & Minimum level of services needed for the people's living \\
\hline
\end{tabular}

As shown in Fig. 3, to establish a BCP, it is necessary first to predict the influence of the pandemic (the potential losses) on the organization. This study focused on the staffing problem considered in the BCP, particularly for the small- and medium-sized enterprises. It is presumed that when the employee absentee rate reaches $40 \%$, most plants will be forced to stop production. However, the company should be able to keep producing products ordered by customers. To prepare for the work force shortage that may result from the pandemic influenza, it is urgently necessary to devise a personnel plan and staff development beforehand.

In the next section, through a case study involving a manufacturing company, the approach for establishing a personnel plan for a BCP is discussed and presented. A simulation is applied to forecast and evaluate the operating rate in a factory.

\section{BUSINESS CONTINUITY PLANNING SIMULATION}

\subsection{System description of a factory}

Z-Company is a Japanese company producing industrial-use machinery and other related equipment components. In 2008, Z-Company had two domestic plants with about 1,400 employees. Z-Company's products are sold in Japan and are exported to Asia, North America and Europe. According to the managers of the company, the sales and production for the ZCompany are seasonal and vary greatly by month. As shown in Fig. 4, it could be observed that the sales peaked in July and fell to a low in October in FY2007.

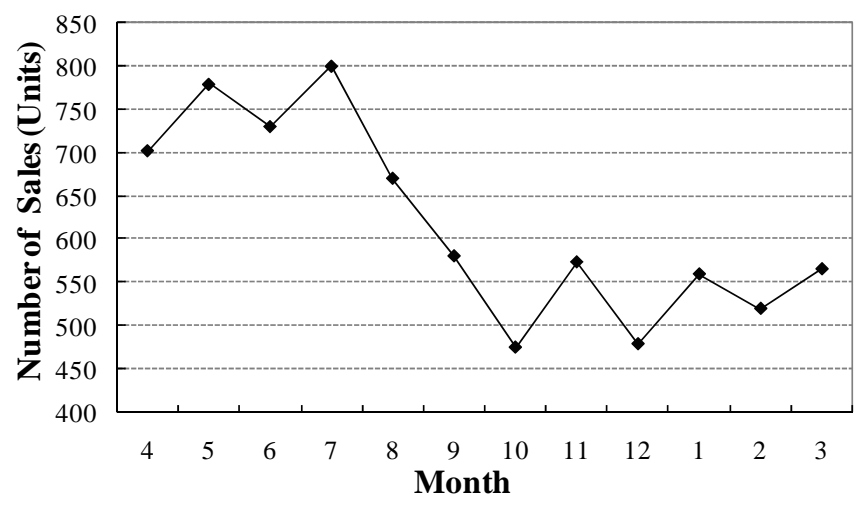

Figure 4: Number of monthly sales in Z-Company (From Apr. 2007 to Mar. 2008). 
The manual assembly line for machine production discussed in this study was operated in a sub-factory located in one of the two plants [10]. About 60 people were working in that assembly line, producing electronic parts for automatic assembling machines. Depending on Depending on demand fluctuation, more or fewer workers were assigned to the line. The manufacturing capability also varies when the workforce changes. The assembly process is shown in Fig. 5.

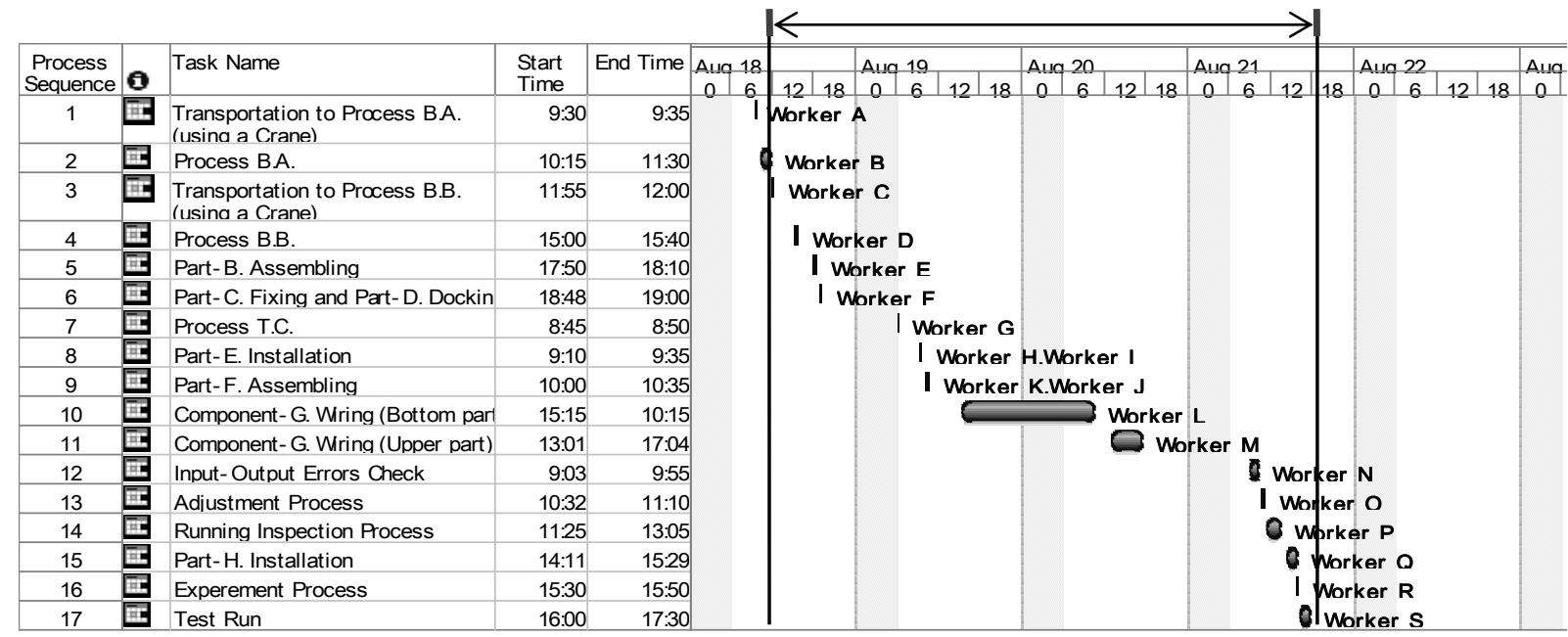

Figure 5: Processes and operations of the factory.

\subsection{Simulation analysis}

Computer-aided simulation provides a method for the following: 1) including random and structural variation in the models; 2) identifying, from among various alternatives, a good solution to production system problems before implementation; and 3) assessing the effects of the interaction of system components [11]. In this study, the simulation technique was adopted to enable researchers to analyze and assess the production capacity of the target assembly line dynamically and to investigate the relationship between production efficiency and manpower assignment in the pandemic environment. The simulation models are programmed in Arena [12] and overlaid on a scaled factory layout.

To establish a BCP addressing the effects of influenza, we need to first predict the influence quantitatively as much as possible. After that, we need to address how these influences could be eliminated or minimized. To conduct an experiment on how influenza affects factory productivity, we first constructed a simulation model named "as-is" model. A screen image for running this simulation model is shown in Fig. 6.

This "as-is" model was programmed based on the normal state of the factory, including the staffing assignment and the production status. The impact of the pandemic on the factory can be predicted quantitatively by using key performance indicators (KPI) to compare the results of experimental models before and after the influenza. In this study, the KPIs are given as throughput, work in process (WIP), wait time, lead time and utilization of resources [1214].

Table II indicates a part of the parameters of input to the "as-is" model. All data used in this study were obtained through long-term research in the factory. Based on the actual production and sales data for one year, the source of the entity and arrival time input to the simulation model was extracted. After the simulation model was constructed, it was verified by removing all time variation and running a single transaction through the model. Furthermore, model validation was accomplished through an interactive process between company staff and the modeller. The results of the analysis were shown to the company staff 
and confirmed through a face-to-face discussion. From the results of this simulation, we can collect and understand data about the productivity of the factory in a normal environment in which no disruptions occur.

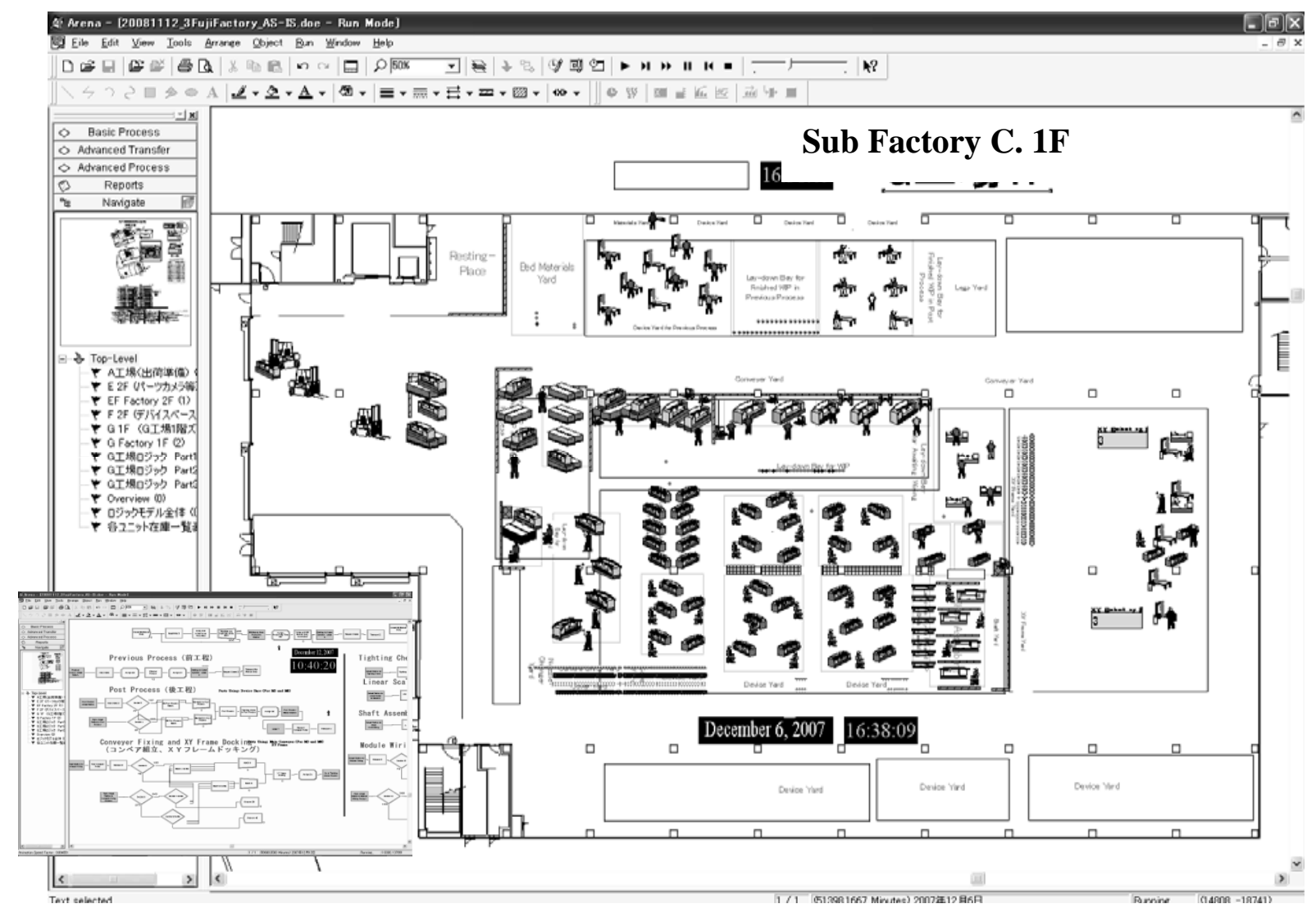

Figure 6: Animation of the "as-is" model.

Table II: List of parameters input to the simulation models (partial).

\begin{tabular}{|c|c|c|c|c|c|}
\hline \multirow[b]{2}{*}{ Process Name } & \multicolumn{2}{|c|}{ Parameter of Processing Time } & \multicolumn{3}{|c|}{ Parameter of Resource } \\
\hline & $\begin{array}{l}\text { Processing Time } \\
\text { for Products of } \\
\text { M3 Type }\end{array}$ & $\begin{array}{c}\text { Processing Time } \\
\text { for Products of } \\
\text { M6 Type }\end{array}$ & $\begin{array}{c}\text { Resource } \\
\text { Type }\end{array}$ & $\begin{array}{c}\text { Number of } \\
\text { Wokers }\end{array}$ & Operation Schedule \\
\hline Process B.A. & $\operatorname{TRIA}(35,91,145)$ & $\operatorname{TRIA}(50,102,160)$ & Worker & 8 & Based on Schedule 1, Schedule 2, Schedule 3 \\
\hline Process B.B. & TRIA(20,47,105) & TRIA(20,66,110) & Worker & 5 & Based on Schedule 1, Schedule 2, Schedule 3 \\
\hline Part-C.and & $\operatorname{TRIA}(20,28,36)$ & $\operatorname{TRIA}(20,28,36)$ & Worker & 2 & Based on Schedule 1, Schedule 2, Schedule 3 \\
\hline Process T.C. & $\operatorname{TRIA}(15,20,25)$ & $\operatorname{TRIA}(15,20,25)$ & Worker & 3 & Based on Schedule 1, Schedule 2, Schedule 3 \\
\hline Part-E. Installation & $\operatorname{TRIA}(8,14,18)$ & $\operatorname{TRIA}(8,14,18)$ & Worker & 1 & Based on Schedule 1, Schedule 2, Schedule 3 \\
\hline Part-F. Assembling & $\operatorname{TRIA}(40,54,68)$ & $\operatorname{TRIA}(40,54,68)$ & Worker & 5 & Based on Schedule 1, Schedule 2, Schedule 3 \\
\hline Component-G. Wiring & TRIA(135,315,477) & $\operatorname{TRIA}(140,317,447)$ & Worker & 25 & Based on Schedule 1, Schedule 2, Schedule 3 \\
\hline \multirow{2}{*}{$\begin{array}{l}\text { Input-Output } \\
\text { Errors Check }\end{array}$} & \multirow[t]{2}{*}{$\operatorname{TRIA}(39,48,59)$} & \multirow[t]{2}{*}{ TRIA(41,50,55) } & Worker & 4 & Based on Schedule 1, Schedule 2, Schedule 3 \\
\hline & & & PC & 4 & Fixed Capacity: Capacity $=1$ (Avialable 24 Hours) \\
\hline \multirow{2}{*}{ Adjustment Process } & \multirow[t]{2}{*}{$\operatorname{TRIA}(25,39,60)$} & \multirow[t]{2}{*}{$\operatorname{TRIA}(25,39,60)$} & Worker & 3 & Based on Schedule 1, Schedule 2, Schedule 3 \\
\hline & & & PC & 3 & Fixed Capacity: Capacity $=1$ (Avialable 24 Hours \\
\hline \multirow{2}{*}{ Running Inspection } & \multirow[t]{2}{*}{$\operatorname{TRIA}(8,28,40)$} & \multirow[t]{2}{*}{$\operatorname{TRIA}(8,28,40)$} & Worker & 3 & Based on Schedule 1, Schedule 2, Schedule 3 \\
\hline & & & Machine & 8 & Fixed Capacity: Capacity $=1($ Avialable 24 Hours $)$ \\
\hline Part-H. Installation & $\operatorname{TRIA}(50,75,122)$ & TRIA(50,75,122) & Worker & 5 & Based on Schedule 1, Schedule 2, Schedule 3 \\
\hline \multirow{2}{*}{ Experement Process } & \multirow[t]{2}{*}{$\operatorname{TRIA}(10,16,25)$} & \multirow[t]{2}{*}{$\operatorname{TRIA}(10,16,25)$} & Worker & 2 & Based on Schedule 1, Schedule 2, Schedule 3 \\
\hline & & & Machine & 1 & Fixed Capacity: Capacity $=1$ (Avialable 24 Hours) \\
\hline \multirow{2}{*}{ Running Test } & \multirow[t]{2}{*}{$\operatorname{TRIA}(6,10,12)$} & \multirow[t]{2}{*}{$\operatorname{TRIA}(6,10,12)$} & Worker & 1 & Based on Schedule 1, Schedule 2, Schedule 3 \\
\hline & & & Machine & 7 & Fixed Capacity: Capacity = 1 (Avialable 24 Hou \\
\hline
\end{tabular}

(Time: Minutes) 


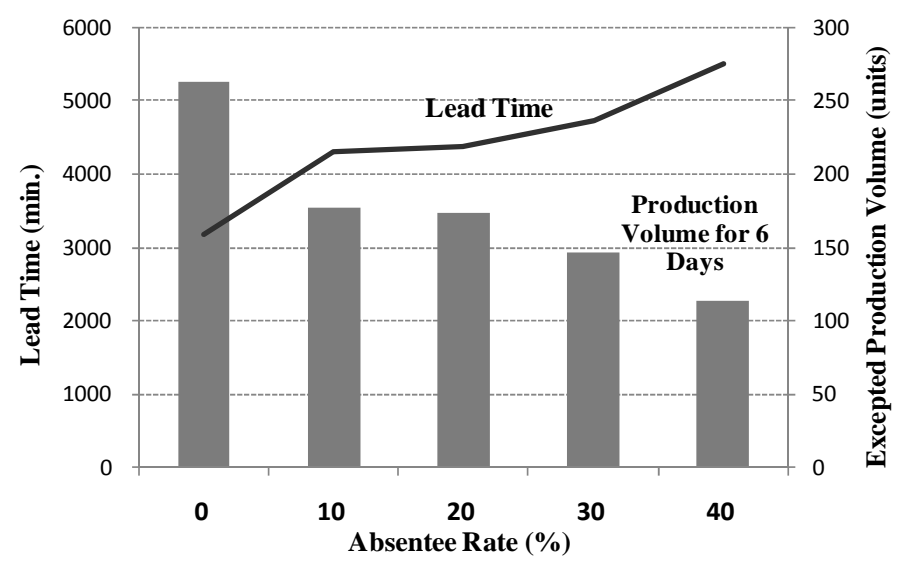

Figure 7: Performance of operations under the selected absentee rates.

When the pandemic influenza occurs and the disease spreads, the employee absentee rate is expected to increase from $10 \%$ to $40 \%$ at maximum. For the ease of understanding, we used absentee rates of $10 \%, 20 \%, 30 \%$ and $40 \%$ in the analysis. Based on these assumptions, we changed the parameters in the simulation model gradually and conducted simulation experiments. The simulation experiments were performed in replicates of 30 . The summarized results of the expected operation rate, lead time and production volume are shown in Fig. 7. The analysis shows that the operation rates and the production efficiency would be decreased drastically in the pandemic environment. If the absentee rate reaches $40 \%$, the factory production will decline to about half of the normal volume. To address this problem caused by pandemic influenza, a BCP needs to incorporate personnel planning. More analysis will be provided in the following subsections.

Once implemented, the simulation model would be used as a tool to experiment with alternative scenarios and to obtain quantitative performance data. While measuring the performance in different alternative scenarios, it is important to evaluate and investigate which personnel planning method is the most desirable [10]. To overcome the shortage of manpower under the pandemic scenario, training workers to have multiple skills may be an effective method.

When developing the BCP, it is important to assume the worst situation and plan for it. In this study, researchers used actual factory conditions to develop six alternative scenarios involving the assignment of multi-skilled workers under the pandemic scenario, in which the absentee rate reach up to 40 percent (the maximum level). The scenarios are shown in Table III and Table IV. In Table IV, the numbers 1 through 12 shown at the top indicate the process ID shown in the first column of the table.

Table III: Alternative scenarios under pandemic situation (absentee rate $=40 \%$ ).

\begin{tabular}{c|l}
\hline Scenario & \multicolumn{1}{c}{ Descriptions } \\
\hline $\mathrm{S}_{1}$ & All employees are multi-skilled workers and available for all manufacturing processes \\
\hline $\mathrm{S}_{2}$ & $\begin{array}{l}\text { The employees can operate the previous or next process in addition to his/her own } \\
\text { assigned process. }\end{array}$ \\
\hline $\mathrm{S}_{3}$ & $\begin{array}{l}\text { The employees can operate the previous or next two processes in addition to his/her } \\
\text { own assigned process. }\end{array}$ \\
\hline $\mathrm{S}_{4}$ & $\begin{array}{l}\text { The employees can operate the specific grouped processes devised based on reality, } \\
\text { which are shown in Table IV. }\end{array}$ \\
\hline $\mathrm{S}_{5}$ & $\begin{array}{l}\text { The employees can operate the specific grouped processes devised based on reality, } \\
\text { which are shown in Table IV. }\end{array}$ \\
\hline $\mathrm{S}_{6}$ & None of the workers are multi-skilled. \\
\hline
\end{tabular}


Table IV: Scenarios of assignment of training multi-skilled workers.

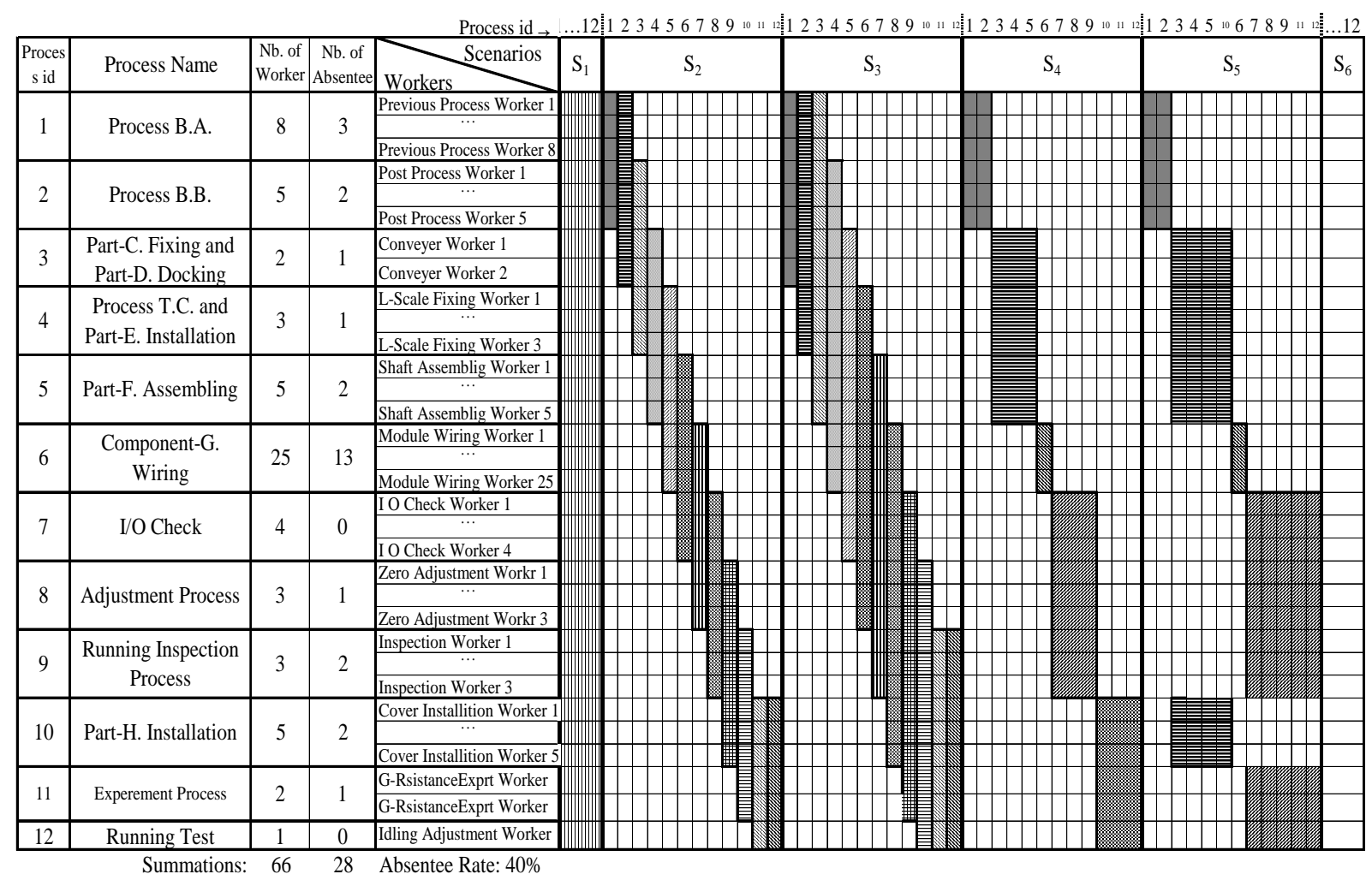

According to the personnel planning scenarios, six simulation models, models $\mathrm{S}_{1}$ to $\mathrm{S}_{6}$, are constructed by adopting the approach of changing the parameters based on the "as-is" model created earlier. After implementation, these six simulations are used to conduct the scenario experiments and collect data for comparison analysis. All of the models are run in thirty replicates. A portion of the analysis results (average values within $95 \%$ C.I.) is shown in Figs. 8 and 9.

Through the comprehensive comparison analysis by KPIs of WIP, Production Volume and Lead Time, as shown in Figs. 8 and 9, the analysis found that when the employee absentee rate reaches the maximum level, there are differences from the experimental results by scenarios of assignment of training multi-skilled workers. As shown in Figs. 8 and 9, the resultant results of scenarios $S_{1}, S_{3}$ and $S_{5}$ indicated comparatively desirable levels. However, because of the number of the processes (i.e., twelve), the burden to the employees and, the training cost, the scenario $S_{1}$ seems to be rather difficult to implement and is obviously unrealistic. Hence, the scenarios $S_{3}$ and $S_{5}$ have remained for conducting further analysis. In order to examine whether there existed statistical differences between scenarios $S_{3}$ and $S_{5}$, the analyses of variance (ANOVA) were performed. In this study, a two-way ANOVA $(\alpha=0.05)$ with 30 replications which were applied for data stratified by the factor of scenarios $\left(\mathrm{S}_{3}\right.$ or $\left.\mathrm{S}_{5}\right)$ and by the factor of products types (M3 or M6).

An ANOVA result for lead time is shown in Table V. It was concluded that lead time was not significantly different not only between the scenarios $S_{3}$ and $S_{5}$ but also between products types. The similar conclusion was drawn form the ANOVA results for WIP and production volume as well. Thus it could be concluded that there was no statistical difference between scenarios $\mathrm{S}_{3}$ or $\mathrm{S}_{5}$ on assigning multi-skilled workers under a pandemic flu environment. Therefore, the company can adopt the scenarios $S_{3}$ or the $S_{5}$ multi-skilled assignment scenarios by performing job training and job enrichment such as cross training before occurrence of crisis, based on the actual situation and its own strategies. 


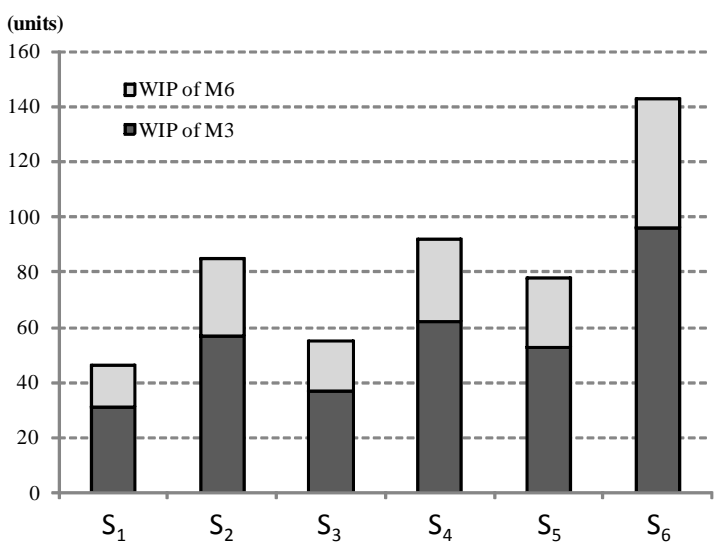

Figure 8: Volume of WIP by scenarios.

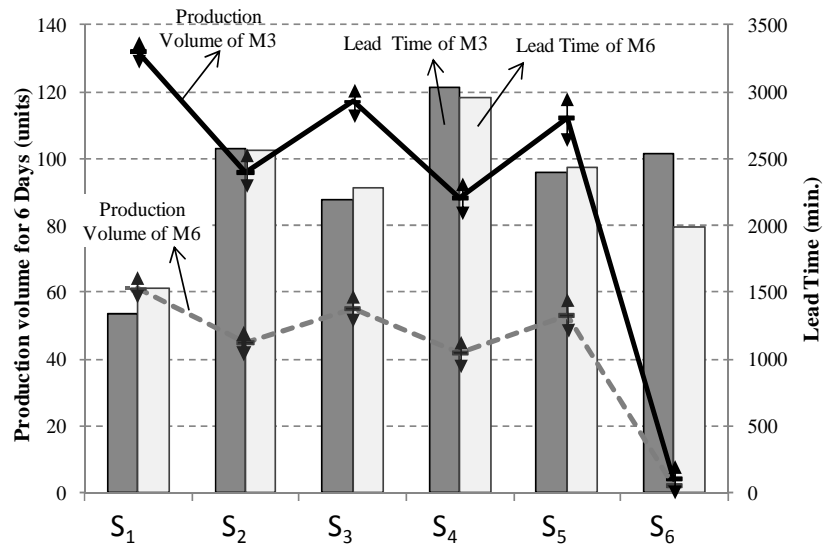

Figure 9: $95 \%$ confidence interval on the average percentage of production volume and lead time.

Table V: Two-way ANOVA with replication of 30 times.

ANOVA for Lead Time $(\alpha=0.05)$

\begin{tabular}{lrrrrrc}
\hline \multicolumn{1}{c}{ Source of Variation } & \multicolumn{1}{c}{ SS } & \multicolumn{1}{c}{ df } & \multicolumn{1}{c}{ MS } & \multicolumn{1}{c}{ F } & P-value & F crit \\
\hline Scenarios $\left(\mathrm{S}_{3}\right.$ or $\left.\mathrm{S}_{5}\right)$ & 7721106 & 1 & 7721106 & 1.9094 & 0.16968 & 3.9229 \\
Products Types $(\mathrm{M} 3$ or M6) & 8085502 & 1 & 8085502 & 1.9996 & 0.16002 & 3.9229 \\
Scenarios $\times$ Products Types & 3713953 & 1 & 3713953 & 0.9185 & 0.33987 & 3.9229 \\
Replication Error & 469064159 & 116 & 4043657 & & & \\
& & & & & & \\
Total & 488584719 & 119 & & & & \\
\hline
\end{tabular}

\section{CONCLUSIONS}

1. The procedure of examining the operation rates and personnel planning is proposed in drawing up a business continuity plan, especially under a pandemic flu environment, by applying a simulation.

2. It is important to establish business continuity planning and disaster planning to cope with the difficulties caused by a disaster or a disruption. The operation rates and production efficiency would decline drastically in a pandemic flu environment. Hence, it is important for a manufacturer to cope with possible disruptions.

3. Cross-training, hiring retired workers and assigning workers for suspended operations is effective for keeping the required number of personnel available for designated operations. Our analysis found that training the multi-skilled worker is effective in helping to overcome a workforce shortage that may occur in the pandemic scenario.

4. The simulation provides the opportunity to test various alternative scenarios of personnel assignment within a system and to evaluate the BCP quantitatively. By combining the use of simulation to BCP, the decision maker can perform effective analysis of the manufacturing system quantitatively as well as qualitatively.

\section{ACKNOWLEDGMENT}

This research was supported by Grant-in-Aid for Young Scientifics (B) (No. 21730296) and Asian CORE Program of Japan Society for the Promotion of Science (JSPS). 


\section{REFERENCE}

[1] Cerullo, V.; Cerullo, M. J. (2004). Business continuity planning: A comprehensive approach, Information Systems Management, Vol. 21, No. 3, 70-78

[2] Finch, P. (2004). Supply Chain Risk Management, Supply Chain Management - An International Journal, Vol. 9, No. 2, 183-196, doi: 10.1108/13598540410527079

[3] Craighead, C. W.; Blackhurst, J.; Rungtusanatham, M. J.; Handfield, R. B. (2007). The Severity of Supply Chain Disruptions: Design Characteristics and Mitigation Capabilities, Decision Sciences, Vol. 38, No. 1, 131-156

[4] Zsidisin, G. A.; Melnyk, S. A.; Ragatz, G. L. (2005). An institutional theory perspective of business continuity planning for purchasing and supply management. International journal of production research, Vol. 43, No. 16, 3401-3420, doi:10.1080/00207540500095613

[5] Ministry of Health, Labour and Welfare of Japan (2005). Pandemic Influenza Preparedness Action Plan of the Japanese Government, from http://www.mhlw.go.jp/english/topics/ influenza/index.html, accessed on 01-09-2010

[6] SME Agency of Japan (2008). BCP Guideline for SME, from http://www.chusho.meti.go.jp/keiei/antei/2008/080418bcp_gude.html, accessed on 01-04-2010

[7] Cabinet Office of Japan (2005). Business Continuity Guidelines $1^{\text {st }}$ ed., from http://www.udri.net/portal/kigyoubousai/guideline01_e.pdf.pdf, accessed on 01-09-2010

[8] BCP Research Group (2009). Introduction to BCP, TOSEISHINPOSHA, ISBN978-4-88614-1842, Tokyo (in Japanese)

[9] WHO (2009). Guidelines for Pharmacological Management of Pandemic (H1N1) 2009 Influenza and other Influenza Viruses (20 August 2009), from http://www.who.int/en/, accessed on 25-102009

[10] Tan, Y. (2010). Simulation analysis of an enhanced lean manufacturing system, Journal of the Japan Society of Logistics Systems, Vol. 10, No. 1, 21-28

[11] Tumay, K. (1995). Business process simulation, Proceedings of the 1995 Winter Simulation Conference, 55-60

[12] Kelton, W. D.; Sadowski, R. P.; Sturrock. D. T. (2007). Simulation with ARENA $4^{\text {th }}$ ed., McGrawHill, New York

[13] Harrell, C.; Gladwin, B. (2005). Productivity Improvement in Appliance Manufacturing, Proceedings of the 2007 Winter Simulation Conference, 1610-1614, doi: 10.1109/WSC.2007.4419780

[14] Tan, Y.; Takakuwa, S. (2007). Predicting the impact on business performance of enhanced information system using business process simulation, Proceedings of the 2007 Winter Simulation Conference, 2203-2211, doi:10.1109/WSC.2007.4419855 